LAWRENCE LIVERMORE N A TION AL LABORATORY

\title{
UCRL-JRNL-202695
}

\section{Chemical Kinetic Modeling of HMX and TATB Laser Ignition Tests}

Craig M. Tarver

March 3, 2004

Journal of Energetic Materials 
This document was prepared as an account of work sponsored by an agency of the United States Government. Neither the United States Government nor the University of California nor any of their employees, makes any warranty, express or implied, or assumes any legal liability or responsibility for the accuracy, completeness, or usefulness of any information, apparatus, product, or process disclosed, or represents that its use would not infringe privately owned rights. Reference herein to any specific commercial product, process, or service by trade name, trademark, manufacturer, or otherwise, does not necessarily constitute or imply its endorsement, recommendation, or favoring by the United States Government or the University of California. The views and opinions of authors expressed herein do not necessarily state or reflect those of the United States Government or the University of California, and shall not be used for advertising or product endorsement purposes. 


\title{
CHEMICAL KINETIC MODELING OF HMX AND TATB LASER IGNITION TESTS
}

\author{
CRAIG M. TARVER \\ Energetic Materials Center \\ Lawrence Livermore National Laboratory \\ Livermore, CA 94551
}

\begin{abstract}
Recent laser ignition experiments on octahydro-1,3,5,7-tetranitro-1,3,5,7terrazocine (HMX) and 1,3,5-triamino-2,4,6-trinitrobenzene (TATB) subjected to laser fluxes ranging from 10 to $800 \mathrm{~W} / \mathrm{cm}^{2}$ produced ignition times from seconds to milliseconds. Global chemical kinetic thermal decomposition models for HMX and TATB have been developed to calculate times to thermal explosion for experiments in the seconds to days time frame. These models are applied to the laser ignition experimental data in this paper. Excellent agreement was obtained for TATB, while the calculated ignition times were longer than experiment for $\mathrm{HMX}$ at lower laser fluxes. At the temperatures produced in the laser experiments, HMX melts. Melting generally increases condensed phase reaction rates so faster rates were used for three of the HMX reaction rates. This improved agreement with experiments at the lower laser fluxes but yielded very fast ignition at high fluxes. The calculated times to ignition are in reasonable agreement with the laser ignition experiments, and this justifies the use of these models for estimating reaction times at impact and shock "hot spot" temperatures.
\end{abstract}

\section{INTRODUCTION}

Accident scenarios involving pressed solid high explosives include heating to thermal explosion, impact formation of localized "hot spots," and shock compression of voids creating very hot regions [1]. Global chemical decomposition models have been developed to predict times to explosion and the location within the explosive charge 
where runaway reaction first occurs [2-4]. These calculations are used as the bases for estimations of the violence of thermal explosions as functions of heating rate, confinement, damage and porosity [5]. Due to the absence of experimental chemical kinetic data at higher temperatures, these models have also been used to estimate the critical conditions for "hot spot" ignition during impact and shock compression scenarios [6] and the growth rates of shock induced hot spots during shock to detonation transition (SDT) processes [7]. They are currently being used to model shock initiation and detonation wave propagation in a grain scale model [8] and in a statistical hot spot reactive flow model being developed in the thermal-mechanical-hydrodynamic coupled computer code ALE3D [9].

Recently Ali et al. [10] heated octahydro-1,3,5,7-tetranitro-1,3,5,7-terrazocine (HMX) and 1,3,5-triamino-2,4,6-trinitrobenzene (TATB) pellets to thermal ignition using two $\mathrm{CO}_{2}$ lasers. The measured times to explosion are in the second to millisecond regime, and the measured average ignition temperatures were $650 \mathrm{~K}$ for $\mathrm{HMX}$ and $708 \mathrm{~K}$ for TATB. These times to explosion are shorter than those that can be measured in most thermal explosion experiments, such as the One Dimensional Time to Explosion (ODTX) apparatus [11]. Thus these rapidly heated laser ignition experiments represent an excellent test of the HMX and TATB global chemical decomposition models. This test helps determine whether these models, normalized to experimental data in the $453 \mathrm{~K}$ to $593 \mathrm{~K}$ range, can be used for predictions of thermal response of HMX and TATB at higher temperatures, such as those occurring in impact and shock induced hot spots. In this paper, the laser ignition experiments are briefly discussed. Then the global HMX and TATB chemical decomposition models are presented. The comparison of the calculated times to ignition are then compared to the experimental measurements in the Results 
section. Finally, some conclusions are drawn, and some future research areas are identified.

\section{EXPERIMENTAL}

Ali et al. [10] used two different $\mathrm{CO}_{2}$ lasers to heat $1 \mathrm{~cm}$ diameter by $6.4 \mathrm{~mm}$ thick pressed pellets of HMX and TATB to thermal ignition. The Edinburgh Instruments Ltd. PL-6 180 Watt laser has a rise time of approximately 2 ms. The PRC Corp. SL1000 1000 Watt laser has a rise time of $0.6 \mathrm{~ms}$. The laser beam profiles and the diagnostics used are fully discussed. For irradiances less than $60 \mathrm{~W} / \mathrm{cm}^{2}$, no differences were observed in the measured ignition delays using the two lasers under atmospheric conditions. TATB exhibited a single ignition time dependence over the entire range of laser fluxes, while the HMX data exhibited two distinct trends with a transition region of high scatter in the 50 to $100 \mathrm{~W} / \mathrm{cm}^{2}$ range. The ignition temperatures measured using fast response thermocouples did not change significantly for the range of irradiances used. Ali et al. [10] also included HMX laser ignition time data from other experimental studies that agreed well with their measurements. Various experimental details, uncertainties and future experimental research were discussed.

\section{CHEMICAL KINETIC DECOMPOSITION MODELS FOR HMX AND TATB}

Three to five step global chemical decomposition models have been developed for several solid high explosives. The HMX chemical decomposition model consists of four reactions and five chemical species. The reaction sequence is [4]:

$\begin{array}{lcc}\text { Beta HMX } & ---->> & \text { Delta } \mathrm{HMX} \\ \text { Delta HMX } & ----> & \text { Solid Intermediates } \\ \text { Solid Intermediates } & ---->> & \text { Gaseous Intermediates }\left(\mathrm{CH}_{2} \mathrm{O}, \mathrm{N}_{2} \mathrm{O}, \mathrm{HCN}, \mathrm{HNO}_{2}, \text { etc. }\right) \\ \text { Gaseous Intermediates } & -----> & \text { Final Products }\left(\mathrm{CO}_{2}, \mathrm{H}_{2} \mathrm{O}, \mathrm{N}_{2}, \mathrm{CO}, \mathrm{C}, \text { etc. }\right)\end{array}$


The major pathways for HMX decomposition have been reviewed by Behrens et al. [12]. The solid - solid beta to delta phase transition is treated as a separate reaction in Eq. (1) [4], whereas previously it had been included with Eq. (2) as one overall endothermic process [2]. Equation (2) describes the initial ring and bond breaking endothermic step(s). HMX decomposition is known to produce as the main intermediate products $\mathrm{CH}_{2} \mathrm{O}$ plus $\mathrm{N}_{2} \mathrm{O}$ under some temperature and pressure conditions and $\mathrm{HCN}$ plus $\mathrm{HNO}_{2}$ under other conditions [12]. Equation 3 is slightly exothermic, and thus most of HMX's chemical energy is released during the gas phase formation of the final stable reaction products by second order gas phase reactions in Eq. (4).

The TATB model is based on less chemical kinetic data than the HMX model and has not changed recently [5]. It consists of three reactions and four species. The TATB sequence is:

TATB

Solid Intermediate A

Solid Intermediate B

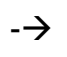

$-\rightarrow$

Solid Intermediate B + Gases

Final gaseous products

It is known that TATB reacts mainly in the condensed phase and that all of the possible $\mathrm{H}_{2} \mathrm{O}$ molecules can be formed during very slow heating leaving $\mathrm{C}_{6} \mathrm{~N}_{6} \mathrm{O}_{3}$ behind [5]. At faster heating rates, the first two reactions, Eq. (5) and (6), are assumed to be

endothermic steps which eliminate $\mathrm{H}_{2} \mathrm{O}$ and perhaps other intermediate gaseous products, such as NO. The third reaction is assumed to be an exothermic, second order 
reaction. Some kinetic data is available and is used for the rates of the three reactions [5]. In the ODTX apparatus, TATB-based explosives exhibit essentially the same times to explosion under heavy confinement and with no confinement $[2,5]$. Thus it is likely that gas phase reactions do not dominate the chemical energy release process in TATB as they do in HMX.

Table 1 lists the thermal property and reaction rate parameters for the HMX decomposition model, and Table 2 lists those for TATB. Both models have been used to calculate times to and locations of thermal explosion for the ODTX and other thermal experiments with various heating rates, degrees of confinement, and geometries [2-5]. These models are used directly to model the laser ignition experiments of Ali et al. [10] by placing a time dependent heat flux boundary condition on the top of the pellet. The experimental uncertainties in the laser flux reaching the solid explosive surface discussed by Ali et al. [10] are not considered in these two-dimensional calculations using the Chemical TOPAZ heat transfer code [13]. The calculated times to thermal ignition for HMX and TATB are compared to experiment in the next section.

\section{RESULTS}

The times to ignition for laser heated HMX and TATB are calculated using the Chemical TOPAZ code with very fine zoning to assure that the calculations have converged to a consistent answer. For these $0.64 \mathrm{~cm}$ thick pellets, 320 zones are sufficient. After the appropriate laser pulse rise time, a constant flux boundary condition is applied to the pellet surface. The HMX and TATB chemical decomposition models in Tables 1 and 2 agree well with slower heating rate and longer time to ignition thermal explosion experiments. Figure 1 shows the comparison between the measured and calculated times to ignition as various laser irradiances for HMX. Figure 2 shows a 
similar comparison for TATB. Both thermal decomposition models agree well with the laser ignition data. The HMX model over-predicts the times to ignition at lower laser fluxes and under-predicts those for high laser fluxes. The TATB model predicts the measured times to ignition very well over the entire range of irradiances. The TATB model is based on less experimental chemical kinetic and thermal explosion data, but appears to agree with this high temperature, short time duration laser driven time to ignition data better than the HMX model does.

One reason for the higher calculated times to explosion for HMX may be that $\mathrm{HMX}$ melts at $558 \mathrm{~K}$ and the average ignition in these experiments is $650 \mathrm{~K}$. HMX melting was not included in the HMX decomposition model for slower thermal events, because almost all of the data is taken at temperatures below its melting point [4]. Inclusion of the endothermic melting process increases the HMX times to explosion slightly, but it is known that organic solid explosives generally react faster in the liquid phase than in the solid phase, because of the greater mobility of liquids and intermediate products [12]. The modern ODTX apparatus [11] has been used to measure three times to thermal explosion for $\mathrm{HMX}$ at temperatures exceeding the melting point. These three times to thermal explosion at the ODTX constant temperatures are listed in Table 3. The new ODTX closes and seals in one to two seconds [11] so these measured times to explosion are meaningful. The three calculated times to explosion using the HMX decomposition parameters listed in Table 1 are shown in Table 3 and are considerably higher than experiment. Incorporating HMX melting as a $56.4 \mathrm{cal} / \mathrm{g}$ endotherm [14] between $557 \mathrm{~K}$ and $559 \mathrm{~K}$ and increasing the natural logs of the frequency factors by 4 and decreasing the activation energies by $4 \mathrm{kcal} / \mathrm{m}$ for reactions 2,3 and 4 results in the shorter ODTX times to explosion listed in Table 3. Applying these faster reaction rates to 
the measured $\mathrm{HMX}$ laser ignition times at various irradiation levels yields the time to explosion curve shown in Fig. 3. The resulting calculated ignition times are closer to the experimental times at lower laser fluxes but farther from experiment at high fluxes.

Liau and Lyman (15) calculated the times to ignition for the HMX laser experiments using a chemical kinetics scheme involving 45 species and 232 gas phase reactions. Their calculated HMX ignition times agreed well with experiment, except in the lower flux range where their model also gave a steeper slope than observed experimentally. When the gas plume was allowed to expand radially to eight times the original area at $2 \mathrm{~cm}$ from the HMX surface, their calculated ignition times at lower laser fluxes agreed more closely with experiment.

\section{CONCLUSIONS}

Two global chemical decomposition mechanisms derived from thermal explosion data in the seconds to days time frame are applied to recent high power laser ignition experiments with times to ignition in the millisecond to second time frame. The overall agreement between the measured and calculated times to ignition is good, especially for TATB. This agreement is certainly reasonable enough for these models to be used to estimate critical temperatures for various hot spot sizes formed during impact and shock initiation processes until such hot spot temperatures and dimensions can be measured experimentally [6-9]. The close agreement with the TATB laser ignition times may imply that gas phase absorption of laser energy is not important for TATB, which agrees with previous conclusions that most of the pre-explosion chemistry of TATB occurs in the condensed phase. On the other hand, HMX decomposition is believed to be very dependent on gas phase and HMX surface reactions [12,15]. Therefore gaseous products of HMX decomposition leaving the irradiated surface may absorb significant 
amounts of laser energy, as discussed by Liau and Lyman [15]. Ali et al. [10] plan to expose HMX and TATB to high laser powers, resulting in faster ignitions that will further test the decomposition models. Chemical kinetic reaction rate experiments on liquid HMX are needed to shed identify increases in reaction rates upon melting.

\section{ACKNOWLEDGEMENTS}

The author would like to thank Arif Ali of the Los Alamos National Laboratory for providing a printout of his experimental data. This work was performed under the auspices of the United States Department of Energy by the Lawrence Livermore National Laboratory under contract no. W-7405-ENG-48. 


\section{REFERENCES}

1. Field, J. E., Bourne, N. K., Palmer, S. J. P., and Walley, S. M. 1992. Phil. Trans. R. Soc. Lond. A 339: 269-299.

2. McGuire, R. R. and Tarver, C. M. 1981. Seventh Symposium (International) on Detonation, Naval Surface Weapons Center NSWC MP 82-334, Annapolis, MD, p. 56-65.

3. Tarver, C. M., Tran, T. D., and Whipple, R. E. 2003. Propellants, Explosives, Pyrotechnics 28: 189-193.

4. Tarver, C. M. and Tran, T. D. 2004. "Thermal Decomposition Models for HMX-Based Plastic Bonded Explosives," Combustion and Flame, in press.

5. Chidester, S. K., Tarver, C. M., Green, L. G., and Urtiew, P. A. 1997. Combustion and Flame 110: 264-280.

6. Tarver, C. M., Chidester, S. K., and Nichols III, A. L. 1996. J. Phys. Chem. 100: 5794 $-5799$.

7. Tarver, C. M. and Nichols III, A. L. 1998. Eleventh International Detonation Symposium, Office of Naval Research ONR 33300-5, Aspen, CO, p. 599-609.

8. Reaugh, J. E. 2002. "Grain Scale Dynamics in Explosives," Lawrence Livermore Laboratory Report UCRL-ID-150388, October 2002.

9. Nichols III, A. L. and Tarver, C. M. 2002. "A Statistical Hot Spot Reactive Flow Model for Shock Initiation and Detonation of Solid High Explosives," Twelfth International Symposium on Detonation, Office of Naval Research, San Diego, CA, August 2002, in press.

10. Ali,A. N., Son, S. F., Asay, B. W., DeCroix, M. E., and Brewster, M. Q. 2003. Combustion Science and Technology 175:1551-1571. 
11. Tran, T. D., Simpson, L. R., Maienschein, J., and Tarver, C. 2001. $32^{\text {nd }}$ International Annual Conference of Franhoeor-Institut fur Chemische Technologie (ICT), DWS Werbeagentur and Verlag GmbH, Karlsruhe, Germany, p. 25-1.

12. Behrens Jr., R., Margolis,S. B., and Hobbs, M. L. 1998. Eleventh International Detonation Symposium, Office of Naval Research ONR 33300-5, Aspen, CO, p. 533542.

13. Nichols III, A. L. and Westerberg, K. W. 1993. Numerical Heat Transfer, Part B, 24: 489- 499 .

14. Lyman, J. L., Liau, Y.-C., and Brand, H. V. 2002. Combustion and Flame 130:185203.

15. Liau, Y.-C. and Lyman, J. L. 2002. Combustion Science and Technology 174:141171. 


\section{TABLE 1. Thermal and Reaction Rate Parameters for the HMX Model}

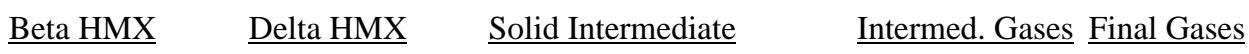

1. Initial Density $\left(\mathrm{g} / \mathrm{cm}^{3}\right)$

$1.85 \quad 1.70$

2. Heat capacity $(\mathrm{cal} / \mathrm{g}-\mathrm{K})$ at:

$\begin{array}{llllll}298 \mathrm{~K} & 0.24 & 0.24 & 0.22 & 0.24 & 0.27 \\ 373 \mathrm{~K} & 0.30 & 0.30 & 0.27 & 0.26 & 0.28 \\ 433 \mathrm{~K} & 0.34 & 0.34 & 0.31 & 0.27 & 0.28 \\ 563 \mathrm{~K} & 0.40 & 0.40 & 0.36 & 0.29 & 0.29 \\ 623 \mathrm{~K} & 0.46 & 0.46 & 0.42 & 0.31 & 0.30 \\ 773 \mathrm{~K} & 0.55 & 0.55 & 0.50 & 0.35 & 0.31 \\ >1273 \mathrm{~K} & 0.55 & 0.55 & 0.50 & 0.42 & 0.35\end{array}$

3. Thermal conductivity (cal/cm-g-K) at:

$\begin{array}{llllll}298 \mathrm{~K} & 1.28 \times 10^{-3} & 1.18 \times 10^{-3} & 1.08 \times 10^{-3} & 9.80 \times 10^{-4} & 1.0 \times 10^{-4} \\ 373 \mathrm{~K} & 1.09 \times 10^{-3} & 1.00 \times 10^{-3} & 9.20 \times 10^{-4} & 8.8 \times 10^{-4} & 1.0 \times 10^{-4} \\ 433 \mathrm{~K} & 1.02 \times 10^{-3} & 9.20 \times 10^{-4} & 8.30 \times 10^{-4} & 8.3 \times 10^{-4} & 1.0 \times 10^{-4} \\ 563 \mathrm{~K} & 8.15 \times 10^{-4} & 8.15 \times 10^{-4} & 8.15 \times 10^{-4} & 8.15 \times 10^{-4} & 1.0 \times 10^{-4} \\ 623 \mathrm{~K} & 7.50 \times 10^{-4} & 7.50 \times 10^{-4} & 7.50 \times 10^{-4} & 7.5 \times 10^{-4} & 1.0 \times 10^{-4} \\ 773 \mathrm{~K} & 1.00 \times 10^{-4} & 1.00 \times 10^{-4} & 1.00 \times 10^{-4} & 1.0 \times 10^{-4} & 1.0 \times 10^{-4} \\ >1273 \mathrm{~K} & 1.00 \times 10^{-4} & 1.00 \times 10^{-4} & 1.00 \times 10^{-4} & 1.0 \times 10^{-4} & 1.0 \times 10^{-4} \\ 4 . \text { Heat of formation }(\mathrm{cal} / \mathrm{g}) & & & & -1339.0\end{array}$

5. Reaction rate parameters $\mathrm{Na}^{\mathrm{x}} \mathrm{qZ} \mathrm{e}^{-\mathrm{E} / \mathrm{RT}}$ (where $\mathrm{Na}$ is mass fraction) 


\begin{tabular}{|c|c|c|c|c|}
\hline$\underline{\text { Reaction }}$ & $\underline{\ln Z}$ & $\underline{\mathrm{E}(\mathrm{kcal} / \mathrm{mol})}$ & $\underline{\text { Reaction Order } x}$ & Heat of Reaction $\mathrm{q}(\mathrm{cal} / \mathrm{g})$ \\
\hline 1 & 48.13 & 48.47 & 1 & +10.0 \\
\hline 2 & 48.7 & 52.70 & 1 & +60.0 \\
\hline 3 & 37.8 & 44.30 & 1 & -133.0 \\
\hline 4 & 28.1 & 34.10 & 2 & -1337.0 \\
\hline
\end{tabular}


Table 2. Thermal and Reaction Rate Parameters for the TATB Model

$\underline{\text { TATB }} \underline{\text { Solid Intermediate A }} \underline{\text { Solid Intermediate B }}$ Gaseous Products

1. Initial Density $\left(\mathrm{g} / \mathrm{cm}^{3}\right)=1.835 \mathrm{~g} / \mathrm{cm}^{3}$

2. Heat capacity (cal/g-K) at:

$\begin{array}{lllll}298 \mathrm{~K} & 0.26 & 0.24 & 0.26 & 0.26 \\ 433 \mathrm{~K} & 0.36 & 0.33 & 0.28 & 0.28 \\ 573 \mathrm{~K} & 0.45 & 0.39 & 0.29 & 0.29 \\ 623 \mathrm{~K} & 0.47 & 0.41 & 0.30 & 0.30 \\ 673 \mathrm{~K} & 0.49 & 0.42 & 0.30 & 0.30 \\ 773 \mathrm{~K} & 0.54 & 0.48 & 0.35 & 0.35 \\ >1273 \mathrm{~K} & 0.54 & 0.48 & 0.35 & 0.35\end{array}$

3. Thermal conductivity (cal/cm-g-K) at:

$\begin{array}{lllll}298 \mathrm{~K} & 2.10 \times 10^{-3} & 1.05 \times 10^{-3} & 5.00 \times 10^{-4} & 1.00 \times 10^{-4} \\ 433 \mathrm{~K} & 1.56 \times 10^{-3} & 7.80 \times 10^{-4} & 3.90 \times 10^{-4} & 1.00 \times 10^{-4} \\ 573 \mathrm{~K} & 1.10 \times 10^{-3} & 5.50 \times 10^{-4} & 2.70 \times 10^{-4} & 1.00 \times 10^{-4} \\ 623 \mathrm{~K} & 1.00 \times 10^{-3} & 5.00 \times 10^{-4} & 2.50 \times 10^{-4} & 1.00 \times 10^{-4} \\ 673 \mathrm{~K} & 1.00 \times 10^{-3} & 1.00 \times 10^{-4} & 1.00 \times 10^{-4} & 1.00 \times 10^{-4} \\ 773 \mathrm{~K} & 1.00 \times 10^{-4} & 1.00 \times 10^{-4} & 1.00 \times 10^{-4} & 1.00 \times 10^{-4} \\ >1273 \mathrm{~K} & 1.00 \times 10^{-4} & 1.00 \times 10^{-4} & 1.00 \times 10^{-4} & 1.00 \times 10^{-4}\end{array}$

4. Heat of formation $(\mathrm{cal} / \mathrm{g})$

$-142.7$

$-92.7$

$+42.7$

$-742.7$

5. Reaction rate parameters $\mathrm{Na}^{\mathrm{x}} \mathrm{qZ} \mathrm{e}^{-\mathrm{E} / \mathrm{RT}}$ (where $\mathrm{Na}$ is mass fraction) 


\begin{tabular}{|c|c|c|c|c|}
\hline$\underline{\text { Reaction }}$ & $\underline{\ln Z}$ & $\underline{\mathrm{E}(\mathrm{kcal} / \mathrm{mol})}$ & $\underline{\text { Reaction Order } x}$ & Heat of Reaction $\mathrm{q}(\mathrm{cal} / \mathrm{g})$ \\
\hline 1 & 48.0 & 60.0 & 1 & +50.0 \\
\hline 2 & 29.8 & 42.0 & 1 & +50.0 \\
\hline 3 & 26.8 & 33.8 & 2 & -700.0 \\
\hline
\end{tabular}


Table 3. HMX Model including Melting and Faster Rates

\begin{tabular}{|c|c|c|c|c|}
\hline Reaction & $\underline{\ln Z}$ & $\underline{E}(\mathrm{kcal} / \mathrm{mol})$ & $\underline{\text { Reaction Order } x}$ & Heat of Reaction $\mathrm{q}(\mathrm{cal} / \mathrm{g})$ \\
\hline 1 & 48.13 & 48.47 & 1 & +10.0 \\
\hline 2 & 52.7 & 48.70 & 1 & +60.0 \\
\hline 3 & 41.8 & 40.30 & 1 & -133.0 \\
\hline 4 & 32.1 & 30.12 & 2 & -1337.0 \\
\hline ODTX Temp(K) & & rimental Time(s) & Calc. Regular rates(s) & Calc. Faster rates(s) \\
\hline 573.05 & & 3.9 & 8.7286 & 3.8184 \\
\hline 563.25 & & 5.1 & 13.892 & 5.1223 \\
\hline 558.65 & & 7.8 & 17.530 & 6.0885 \\
\hline
\end{tabular}




\section{FIGURE CAPTIONS}

Figure 1. Experimental and Calculated Ignition Times versus Laser Irradiance for HMX

Figure 2. Experimental and Calculated Ignition Times versus Laser Irradiance for TATB

Figure 3. HMX Times to Ignition - Experimental and Calculated with Regular and Faster Reaction Rates 


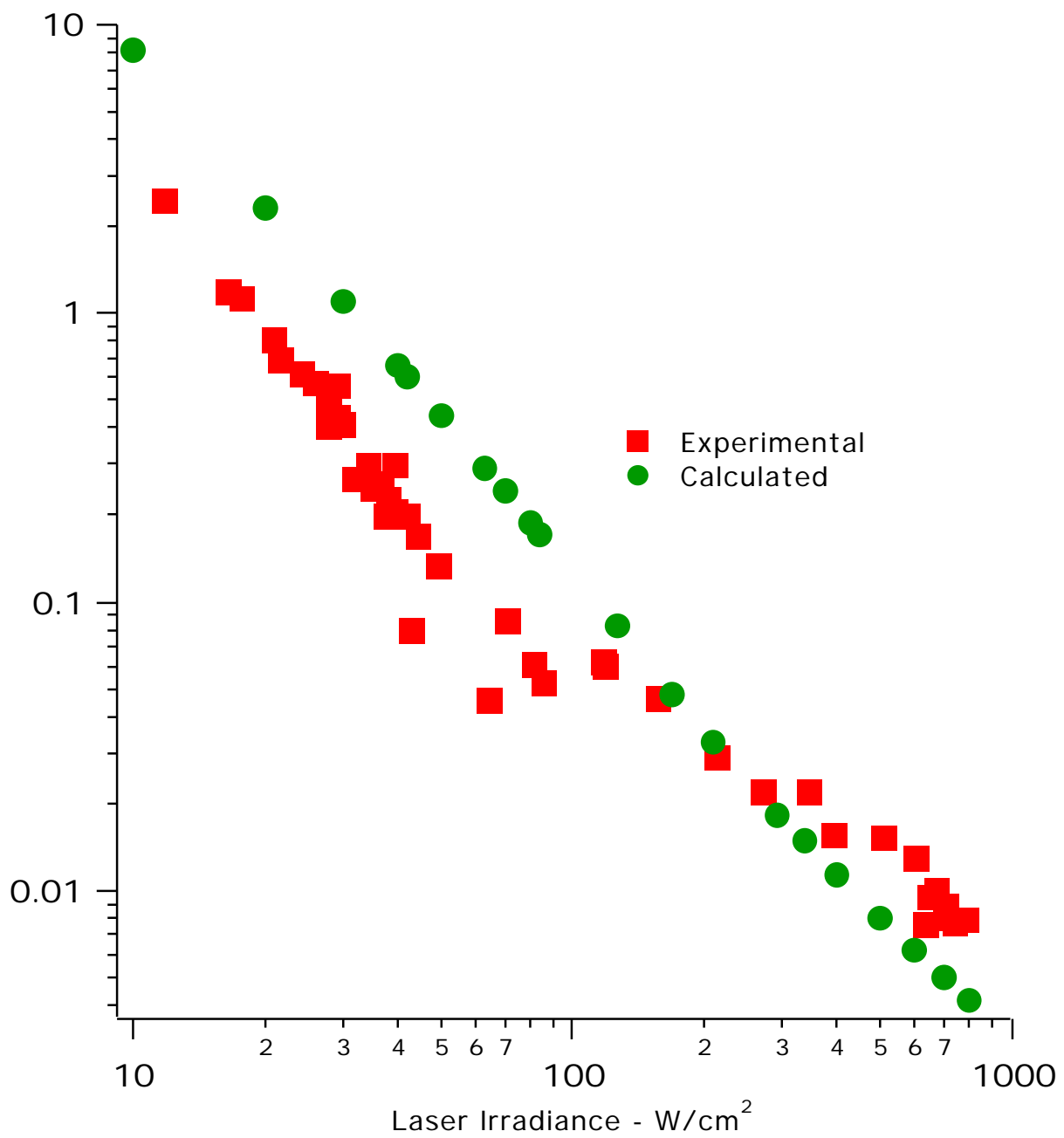

Figure 1. Experimental and Calculated Ignition Times versus Laser Irradiance for HMX 


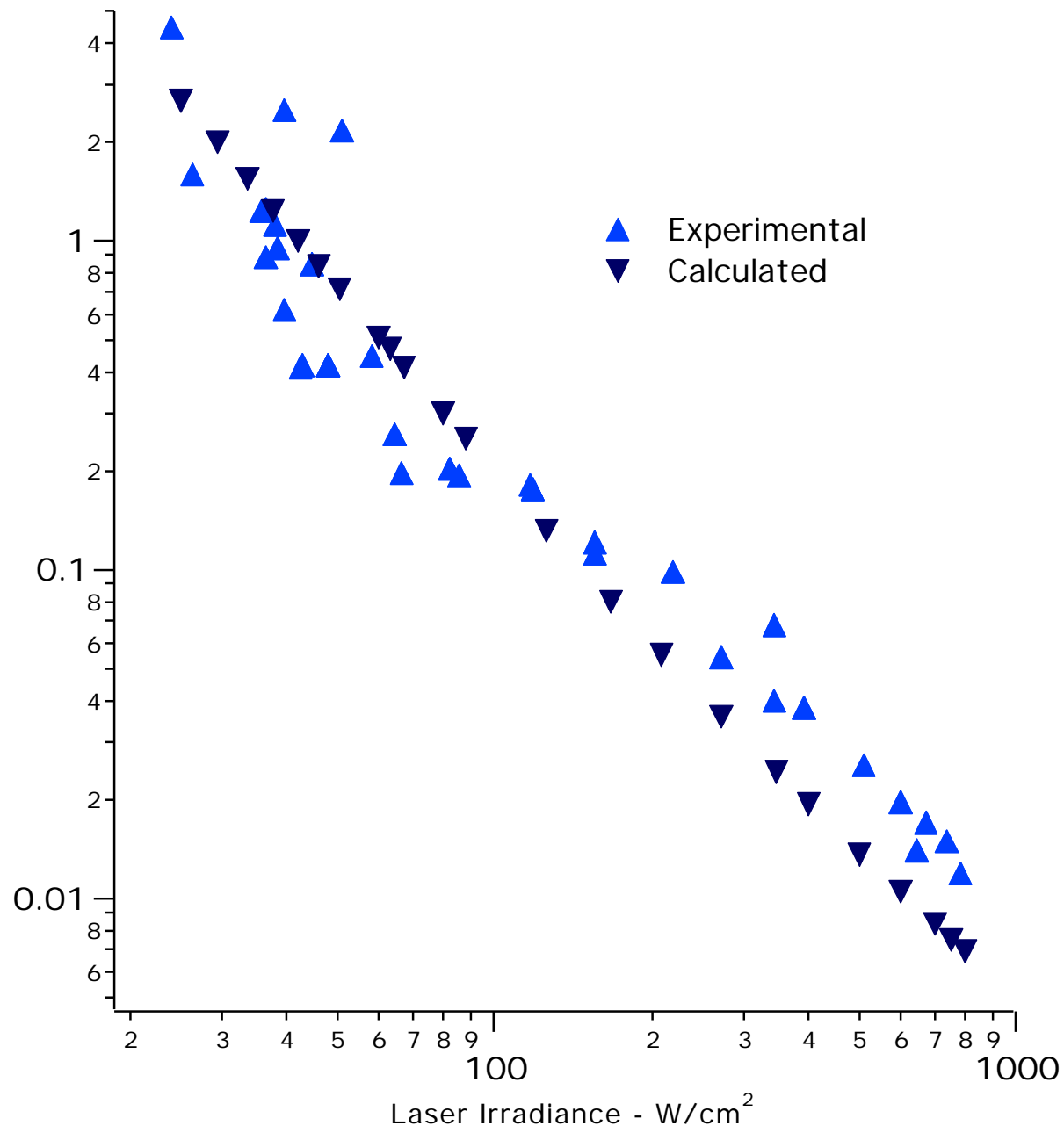

Figure 2. Experimental and Calculated Ignition Times versus Laser Irradiance for TATB 


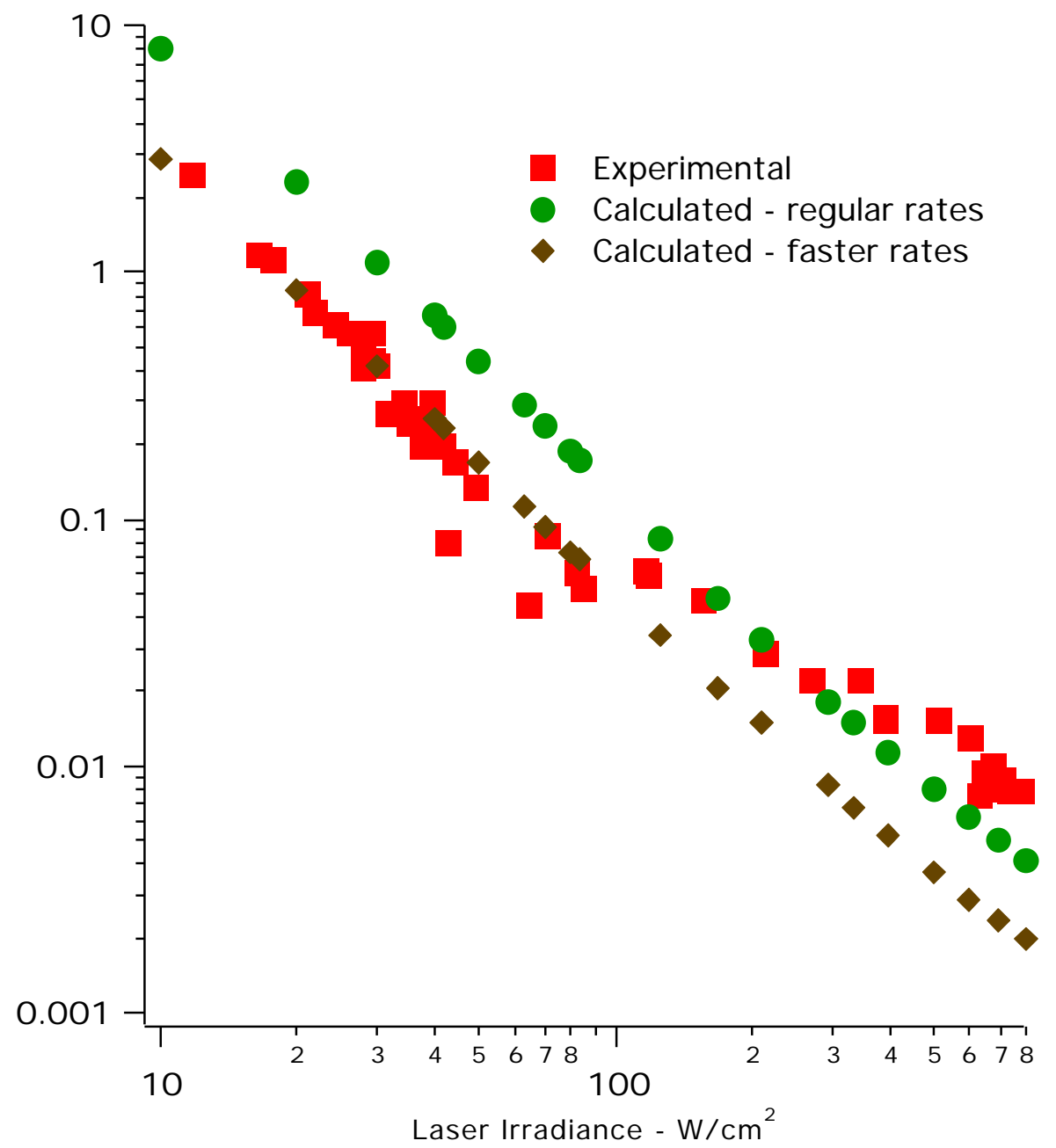

Figure 3. HMX Times to Ignition - Experimental and Calculated with Regular Rates and Faster Reaction Rates

This work was performed under the auspices of the U.S. Department of Energy by the University of California, Lawrence Livermore National Laboratory under Contract No. W-7405-Eng-48. 